\title{
Food Security Status for the Household: A Case Study of Al-Qadarif State, Sudan (2016)
}

Mohamed OA Bushara*and Ibrahim $\mathbf{H H}$

University of Gezira, WadMedani, Gezira State, Sudan

*Corresponding author: Dr Mohamed OA Bushara. University of Gezira, WadMedani, Gezira State, Sudan, Tel: +249511826694; E-mail: mosman@uofg.edu.sd Rec date: April 20, 2017; Acc date: August 02, 2017; Pub date: August 15, 2017

Copyright: (c) 2017 Bushra MOA, et al. This is an open-access article distributed under the terms of the Creative Commons Attribution License, which permits unrestricted use, distribution, and reproduction in any medium, provided the original author and source are credited.

\begin{abstract}
Food security is under focused issue in Sudan and Al-Qadarif State is not apart from that. According to the integrated food security phases classification (IPC) report April 2015, about $60 \%$ of the population suffering from food insecurity in the state. This problem needs to be solved by a clear and sound policies and strategies. The main objective of this study is to evaluate the food security situation in the state, using a module concerning the demand side and to investigate and evaluate the Food Security and Nutrition (FSN) status in the state. To achieve this objective primary data were collected by the mean of questionnaires targeting house hold (394) sample size has been determined by using the Kerjcie and Morgan table, the household questionnaire was to determine the status of the food security within the state, using the USA. Household Food Security Survey Module: six-item short, and to determine the coping strategies of the household. The main results of this research are that: there only $9 \%$ of the households in high or marginal food security situation and the main factors that affecting the household food security status are age and job with significant $P$ value 0.002 and 0.013 respectively. About $60.2 \%$ use borrowing from others as one of their coping strategy. Finally, the main recommendation of this study is to build a food security and nutrition policy/strategy putting the natural resources conservation in consideration.
\end{abstract}

Keywords: Food security; Household; Coping strategies; Al-Qadarif state

\section{Introduction}

\section{Background}

Food security is a hot issue now a day all over the world, the world summit on food security, which held from 16th to 18th of November 2009 in Rome, stated some strategic objectives, which were:

- To reduce respectively the proportion and the number of people who suffer from hunger and malnutrition by half by 2015 .

- Join our efforts and expertise to work in the Global Partnership for Agriculture, Food Security and Nutrition-building on existing structures to enhance governance and cooperation to promote better coordination at global, regional and national levels and ensure that national and regional interests are duly voiced and considered.

- Reverse the decline in domestic and international funding for agriculture, food security and rural development in developing countries, and promote new investment to increase sustainable agricultural production and productivity, reduce poverty and work towards achieving food security and access to food for all.

- Proactively face the challenges of climate change to food security and the need for adaptation of, and mitigation in, agriculture, and increase the resilience of agricultural producers to climate change, with attention to small agricultural producers and vulnerable populations. To achieve these objectives, we need to follow the five rome principles for sustainable global food security; the first principle is to Invest in country-owned plans, aimed at channelling resources to well designed and results-based programmes and partnerships [1].
According to the document that produced by FAO of the United Nations to determine the food security state in the world in meeting the 2015 international hunger targets, about, 795 million people are undernourished globally, down 167 million over the last decade, and 216 million less than in 1990-1992. The decline is more pronounced in developing regions, despite significant population growth. In recent years, progress has been hindered by slower and less inclusive economic growth as well as political instability in some developing regions, such as Central Africa and Western Asia [2].

Until 2011, it was, geographically, the largest country in Africa. The total area of Sudan is now 1,861,484 square kilometres [3]. According to the Central Bureau of Statistics, Sudan, the population was about 30.9 million in 2008 census, $29.8 \%$ of them were urban, and the rest $70.2 \%$ were rural population [4].

According to the country's agricultural policy was changed in 1997 to attain greater food self-sufficiency. It focused on reducing the area of cotton in production because of a shortage of irrigation water; and instead replaced the crop with wheat and sorghum, which require less water.

The hope was that, regardless of the inevitable reduction in export revenue, any increases in food production in the long run would mitigate the increasing effects of drought and food shortage and reduce cereal imports [5]. Mechanized rain-fed agriculture also expanded. In addition to land allocation policies, this led to the displacement of subsistence farmers and nomads, and dismantled traditional systems of communal ownership and management [6].

According to the 2008 census, the total population of Al-Qadarif state is $1,336,662$ persons with an annual population growth rate of 4.7 percent, which is higher than the national growth rate [7]. 


\section{Problem statement}

According to the Integrated Food Security Phase Classification (IPC) report April (2015) [8], which is a set of tools and procedures to classify the nature and severity of food insecurity for decision support. The IPC classifies areas with acute food insecurity into five phases: minimal, stressed, crisis, emergency and famine. Each of these phases has different implications for response objectives.

The state food security is in a very unpleasant situation, about $60 \%$ of the population suffering from food insecurity and that due to the increasing in the commodity prices.

According to the Integrated Food Security Phase Classification (IPC) phases, the total population of Al-Qadarif state is about $(1,911,614)$ persons distributed as follow:

- Phase 1 (None/Minimal): about 757916 (40\%) of the total population of the state.

- Phase 2 (Stressed): 872406 (45.6\%) of them.

- Phase 3(Crises): 273515 (14\%) of them.

Only 7777 ( $0.4 \%)$ of the total population is in phase 4 (Emergency), and none of them in phase 5 (Famine) [8]. The IPC report is concerning the production side which affecting only the availability pillar of food security. So, another tool needed to investigate the household food security, concerning the other food security pillars which are: access to food, utilization and sustainability.

\section{Objectives of the Study}

This objective will be achieved by focusing on some specific and organizational objectives which are:

- To provide current information on food security and nutrition of Al-Qadarif state households.

- To evaluate the food security status in the state, using a module concerning the demand side (USA household food security survey module: six-item short form).

The importance of this paper came from the fact that Al-Qadarif state is one of the most important mechanized rain-fed agricultural areas in Sudan and one of the irrigated schemes is also located in the state, that is Rahad Agricultural Corporation. The total population of the state is 1,336,662 persons with an annual population growth $4.7 \%$, which is higher than the national growth [7]. The above facts reflect the potential of the State in food production and consumption. Also, this study is very important to cover the information gap about food security in the state.

\section{Literature Review}

\section{Food security}

Food security is an essential element of poverty alleviation, Food and Nutrition Security (FNS) has evolved dramatically during the last decades in theory and practice. There are many definitions concerns food security and nutrition, in this section we will try to provide some basic information about the definitions and frame work of the food security.

\section{Food security definition}

The definition of FNS has evolved considerably over time. The starting point of 'food security' was food availability to balance unequal food distribution regionally and nationally. However, it was rapidly accepted that availability, though a necessary element, is not sufficient for food security, because food may be physically existent but inaccessible for those most in need. According to the accepted definition, food security is "adequate access to food for all people always for an active, healthy life". Food is here defined as any substance that people eat and drink to maintain life and growth. As a result, safe and clean water is an essential part of food commodity [9].

The committee on world food security stated that: food security exists when all people, always, have physical, social and economic access to sufficient, safe and nutritious food that meets their dietary needs and food preferences for an active and healthy life. The four pillars of food security are availability, access, utilization and stability. The nutritional dimension is integral to the concept of food security and to the work of Committee on World Food Security (CFS) [9] and CFS [2].

Food security incorporates a measure of resilience to future disruption or unavailability of critical food supply due to various risk factors including droughts, shipping disruptions, fuel shortages, economic instability, and wars.

\section{Food stability}

Refers to the ability to obtain food over time.

\section{Food access}

Refers to the affordability and allocation of food, as well as the preferences of individuals and households.

\section{Food availability}

Relates to the supply of food through production, distribution, and exchange.

\section{Food security and nutrition pillars or dimensions}

According to the definitions above, the food security and nutrition concept built up of four pillars, these pillars are:

- Food availability.

- Food accessibility.

- Food utilization.

- Food stability or sustainability

\section{Food security and nutrition measures}

Measuring food security is a highly diverse field of action and requires a careful selection of the indicators and techniques employed during assessment. Indicators and sets of indicators might work well in a setting but might not be appropriate for another. 


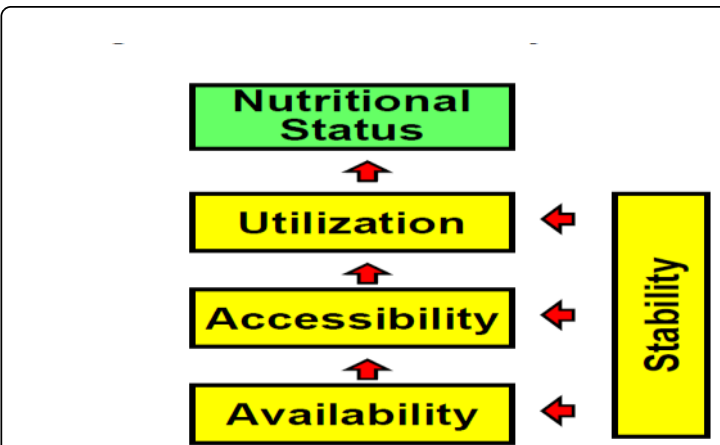

Figure 1: Food security and nutrition conceptual framework [9].

The following Figure 1 illustrates the relationship among the categorical elements within the conceptual framework of food security.

How is food security measured: Food security surveys can, as all surveys, be subject to errors due to biased/mal interpreted questions and biased/mal interpreted answers (in a participants' experience, despite good training, enumerators misunderstood a question and ended up affecting the whole result of the survey). On the other hand, objective measures such as anthropometrics or more detailed assessments of diet components remain less used and can be much more complex [10].

The full range of food insecurity and hunger cannot be captured by any single indicator. Instead, a household's level of food insecurity or hunger must be determined by obtaining information on a variety of specific conditions, experiences, and behaviours that serve as indicators of the varying degrees of severity [11].

The choice of methods and indicators should be driven by the aim of the measurements (targeting, monitoring, evaluation, etc.) and by the audience to which the measurements are directed (analysts, researchers, community leaders, policy makers, etc).

Following FAO [12], we identify five general types of methods/ indicators. The first indicator can be labelled undernourishment, a measure commonly identified with the Food and Agriculture Organization of the United Nations (FAO). This FAO method begins with an estimate of the per capita dietary food energy supply, derived from aggregate food supply data. Assumptions regarding the distribution of this supply across households are made based on the income or consumption distribution, or other available data. The proportion of the undernourished in the total population is then defined as that part of the distribution lying below a minimum energy requirement level [13]. The FAO measure is useful for comparisons across countries and over time.

A second group of indicators, which can be termed food intake, measures the amount of food consumed at the individual or household level. Indicators at the individual level can be obtained directly by measuring actual food intake through several techniques. Food intake surveys, however, are relatively rare, given its cost considerations. Instead, food consumption is usually measured indirectly through household surveys. Household surveys in general, and multipurpose household surveys, are aimed at assessing living standards, not just food security. Although they are time-, resource and skill-intensive, they are now regularly implemented in many countries. Household- level data can be used to construct several measures of food insecurity, including food energy deficiency and poor diet quality and diversity.

The third approach to the assessment of dietary deficiencies is to measure food utilization through nutritional status. Anthropometric measures of children under age five are regularly collected in random sample surveys in many countries. Anthropometric measures, as outcome measures, are well suited for monitoring and evaluating interventions, and can be collected with socioeconomic information to analyse the determinants of malnutrition. Anthropometric attainment, however, is a nonspecific indicator, because it is the result not only of food intake, but also of factors such as sanitation, health and childcare practices. Since nutritional status is an individual-level indicator, it has distinct advantages. For example, it does not mask food insecurity in seemingly food secure households when intra-household allocation rules result in unequal distribution of food resources. This is a problem for both objective and subjective measures, where, for example, one household member responds (e.g. the head) perhaps on basis his/her response on his/her own situation. However, as nutritional status is only available for young children, it has limited power in describing food security for the broad population.

Fourth, food availability is of little use if households or individuals do not have enough financial or productive resources to acquire food. The fourth group of indicators revolves around the concept of access to food and can be proxy by wealth status, measured by total consumption, expenditures or income. Access-to-food indicators, and income, have served as the main food security indicator in many countries. The link between access and a given wealth proxy breaks down when local markets are not functioning, as in the case of war or disaster $[12,14]$.

Finally, the last approach revolves around the concept that even if households are not currently undernourished, they may be at risk or vulnerable to future deprivation. Vulnerability is an inherently dynamic concept which expresses ex-ante vulnerability and ex-post outcomes. Because it is an expression of a 'future state of the world' which, by definition, we do not know a priori, vulnerability is difficult to measure [15] vulnerability is often gauged through qualitative or 'self-assessment' indicators of food insecurity, capturing dimensions which are difficult to isolate with traditional quantitative measures, especially in the absence of panel data. Households may regard themselves as hungry, even if there are no recognizable signs of under nutrition. Further, even if households are not currently undernourished, they may have a significant probability, or wellfounded fear, of future deprivation. Other measures of vulnerability to food deprivation also drawn from household surveys include the share of income spent on food and various coping-strategy indices.

In terms of self-assessment indicators, the United States Government pioneered the approach of assessing household food security based on a score derived from 18 questions on food-related behaviours and conditions that are known to be associated with food deprivation [16]. Many developing countries have successfully implemented similar methodologies [17]. This type of survey has been piloted extensively in Brazil, and a module has recently been included in that country's biannual national income survey. It also recently formed the centrepiece of a large food security study in Yemen and has been tested and applied in Bangladesh [18]. Reduced forms of these subjective modules are found in many recent standard national household surveys, such as the World Bank's Living Standards Measurement Surveys (LSMS), and focus on respondents' perceived assessment of individual or household food security situation. One of 
the questions most commonly asked is called the consumption adequacy question (CAQ), and is generally worded as follows: 'Concerning your food consumption, which of the following is true?' Answers are generally coded as: (a) more than adequate, (b) just adequate, (c) less than adequate. The recent trend in several countries such as Brazil, Yemen, and Bangladesh to redesign a food security index based on local conditions and notions of food consumption is a crucial step forward, and should be encouraged in other countries carrying out LSMS-type household surveys.

The inclusion of a contextually sensitive module like that of the USA into household surveys in developing countries, reflecting also future vulnerability, thus provides an excellent opportunity to validate externally 'subjective' indicators, both at the population level and at the level of the individual household.

What is the household food security scale: Wrote a guide book and revise it in 2000, in this guide book they stated the following concepts: The set of food security questions included in the core survey module can be combined into a single overall measure called the food security scale? This is a continuous, linear scale which measures the degree of severity of food insecurity/hunger experienced by a household in terms of a single numerical value. These scale values vary across a wide range that expresses the full range of severity of food insecurity/hunger as observed in USA households. The unit of measure used for the scale is a matter of convention. For the main presentation of the measure and methods in this Guide, the unit of measure has been chosen such that the full range of severity measured by the standard USA food security scale is expressed by numerical values ranging from 0 to 10 .

The statistical procedure that determines a household's scale value is rather complicated, but fundamentally it depends on the number of increasingly severe indications of food insecurity that the household has experienced, as indicated by affirmative responses to the increasingly severe sequence of survey questions. A household with a scale value of 6 , for example, has responded affirmatively to more, and typically to more severe, indicators of food insecurity than a household with a scale value of 3 . A household that has not experienced any of the conditions of food insecurity covered by the core module questions will be assigned a scale value of 0 , while a household that has experienced all of them will have a scale value close to 10 .

In general, the set of core-module questions works systematically together to provide a measurement tool for identifying, with considerable sensitivity, the level of severity of food insecurity/hunger experienced in a household. Prior to the application of scaled measurement methods to the phenomenon of food insecurity/hunger, a common way of thinking was to see this as a simple, either-or condition, capable of being identified by one or two indicators. Earlier discussion often focused on which indicator, or small set of indicators, was the "right" one. By contrast, the conceptual and technical advances achieved over the last 15 years in measuring food insecurity and hunger have emphasized the continuity of the phenomenon, with hunger understood as a more severe stage "nested within" the broader condition of food insecurity. To guard against simplistic interpretations, documentation for the original 1995 CFS food security supplement emphasized the systematic nature of the core module in the following language:

Responses to individual items in this supplement are not, taken alone or in themselves, meaningful measures of food insufficiency, food insecurity, or hunger, and should not be used in such a manner.
In interpreting the scale, it also is important to remember that what it measures is the sufficiency of household food as directly experienced by household members and not necessarily the nutritional adequacy of diets as a nutritionist would measure it. It is reasonable to expect that households with higher scale values have nutritionally less adequate diets than households with lower scale values, but one cannot draw that conclusion from the scale values alone.

Note also that the scale represents the condition of household members as a group, not necessarily the condition of any person in the household. Some questions apply to the household, such as "the food we bought just didn't last, and we didn't have money to get more." Others ask about the experience of adults in the household as a group, or children as a group.

If the household includes more than one adult or more than one child, the core-module questions do not tell us how many or which of the adults or children experienced the condition. In the national data, most households have scale values of 0 , indicating that within the past year they did not experience any of the conditions of food insecurity covered in the core module questions. Only a tiny fraction of households has values close to the most severe level of food insecurity measured by the questions [19]. Surveys measuring food insecurity for special populations-particularly low-income populations-usually show higher average scale values, but it is still likely that in current USA population surveys most household scale values will be concentrated at the lower end of the range.

How is the household's food security status determined: It is often useful, both for policy and research purposes, to simplify the food security scale into a small set of categories, each one representing a meaningful range of severity on the underlying scale, and to discuss the percentage of the population in each of these categories. Four categories have been defined for this purpose:

Food secure: Households show no or minimal evidence of food insecurity.

Food insecure without hunger: Food insecurity is evident in household member's concerns about adequacy of the household food supply and in adjustments to household food management, including reduced quality of food and increased unusual coping patterns. Little or no reduction in member's food intake is reported.

Food insecure with hunger (moderate): Food intake for adults in the household has been reduced to an extent that implies that adults have repeatedly experienced the physical sensation of hunger. In most (but not all) food-insecure households with children, such reductions are not observed at this stage for children.

Food insecure with hunger (severe): At this level, all households with children have reduced the children's food intake to an extent indicating that the children have experienced hunger. For some other households with children, this already has occurred at an earlier stage of severity. Adults in households with and without children have repeatedly experienced more extensive reductions in food intake.

Sometimes it is preferable to combine the third and fourth groups into a single broader category and to use the term food insecure with hunger for the combined categories. 


\section{USA household food security survey module: Six-item short form}

The six-item short form of the survey module and the associated six-item food security scale were developed by researchers at the National Centre for Health Statistics in collaboration with ABT Associates Inc. [20]. Economic Research Service (ERS) conducted additional assessment of classification sensitivity, specificity, and bias relative to the 18 -item scale.

If respondent burden permits, use of the 18-item USA household food security survey module or the 10-item USA adult food security survey module is recommended. However, in surveys that cannot implement one of those measures, the six-item module may provide an acceptable substitute. It has been shown to identify food-insecure households and households with very low food security with reasonably high specificity and sensitivity and minimal bias compared with the 18-item measure. It does not, however, directly ask about children's food security, and does not measure the most severe range of adult food insecurity, in which children's food intake is likely to be reduced.

Household coping strategies: "What do households do when they don't have enough food, and don't have enough money to buy it?"

People respond to conditions under which they do not have enough to eat, and various means of "coping" is what people must do when they do not have enough food. The more people must cope, the less food secure they are. Household decision-makers (usually, though not always, women) organize the resources at their disposal to limit the short-term effects of not having enough to eat. People generally know how much is "enough" and seek the best options for ensuring that they eat enough. People start to change their consumption habits when they anticipate a problem. They don't wait until food is completely gone.

In their article entitled "developing coping strategies index: field methods manual" Maxwell and Cadwell [21] have stated that there are two basic types of coping strategies. One includes the immediate and short-term alteration of consumption patterns. The other includes the longer-term alteration of income earning or food production patterns, and one-off responses such as asset sales. While it is important to understand longer-term livelihood strategies in an emergency, various researchers have shown that the management of short-term consumption strategies is an accurate indicator of acute food insecurity.

Typically, food insecure households employ four types of consumption coping strategies:

- First, households may change their diet. For instance, households might switch food consumption from preferred foods to cheaper, less preferred substitutes.

- Second, the household can attempt to increase their food supplies using short-term strategies that are not sustainable over a prolonged period. Typical examples include borrowing, or purchasing on credit. More extreme examples are begging or consuming wild foods, immature crops, or even seed stocks.

- Third, if the available food is still inadequate to meet the needs, households can try to reduce the number of people that they must feed by sending some of them elsewhere (sending the kids to the neighbour's house when those neighbours are eating).

- Fourth, and most common, households can attempt to manage the shortfall by rationing the food available to the household (cutting portion size or the number of meals, favouring certain household members over other members, or skipping whole days without eating).

All these types of behaviour indicate a problem of household food insecurity, but not necessarily problems of the same severity. A household where no one eats for an entire day is clearly more food insecure than one where people have simply switched from consuming rice to cassava. The basic idea is to measure the frequency of these coping behaviours (how often is the coping strategy used?) and the severity of the strategies (what degree of food insecurity do they suggest?). Information on the frequency and severity is then combined in a single score, the coping strategies index, which is an indicator of the household's food security status. It considers only the coping strategies that are important in a local context.

\section{State of Sudan food security}

As of February 2016, more than 3.5 million people in Sudan face Stressed (IPC Phase 2) and Crisis (IPC Phase 3) acute food insecurity. Most of these populations are in conflict-affected areas of Darfur, South Kordofan, West Kordofan, and Blue Nile States, with additional pockets of stressed (IPC Phase 2) populations in drought-affected areas of Kassala, North Kordofan, North Darfur, Red Sea and White Nile States. About $55 \%$ to $60 \%$ of the current food insecure population is in Darfur and $12 \%$ in South Kordofan. Crisis (IPC Phase 3) acute food insecurity is mainly among internally displaced persons (IDPs) in SPLM-N-controlled areas of South Kordofan and IDPs in Darfur displaced in the last six months due to conflict (Figure 2).

The June to October 2015 rainy season began 20 to 40 days late in many parts of Sudan, and was followed by below-average rainfall and significant dry spells during August/September, particularly in key surplus-production areas such as Al Qadarif, Kassala, Sinnar, White Nile, West Darfur, and South Darfur States. According to the preliminary findings of the 2015/2016 annual Crop and Food Supply Assessment Mission M) [22] report, staple food production in Sudan was about 25 percent below the last five-year average, and about $55 \%$ below 2014/2015 levels, when the production was almost double the five-year average.

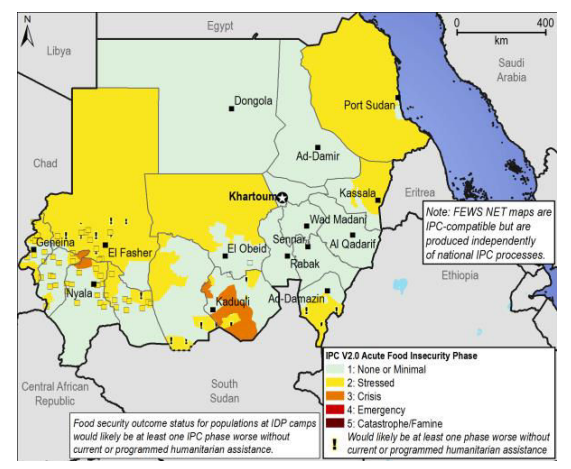

Figure 2: Current food security outcomes, February 2016 [23].

\section{Food security status of the households}

In November and December 2010, an Assessment Mission (AM) was conducted by the Food and Agriculture Organization of the 
United Nations (FAO) and the Government of Sudan to determine crop production and food supply in the northern states of Sudan.

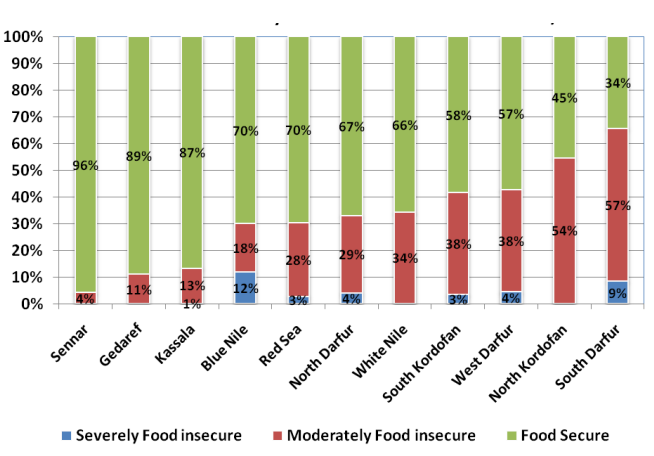

Figure 3: Food security situation of Sudan in October/November $2010[10]$.

Figure 3 shows that the three eastern states Sinnar Al-Qadarif and Kassala have the highest score of food security and no households in the severely food insecure category [10].

Some coping strategies: Households in North Sudan apply a variety of coping strategies, the most common being to rely on less preferred or less expensive food or eat borrowed food or borrow money to buy food, and more severely to reduce the number of meals eaten in one day [10].

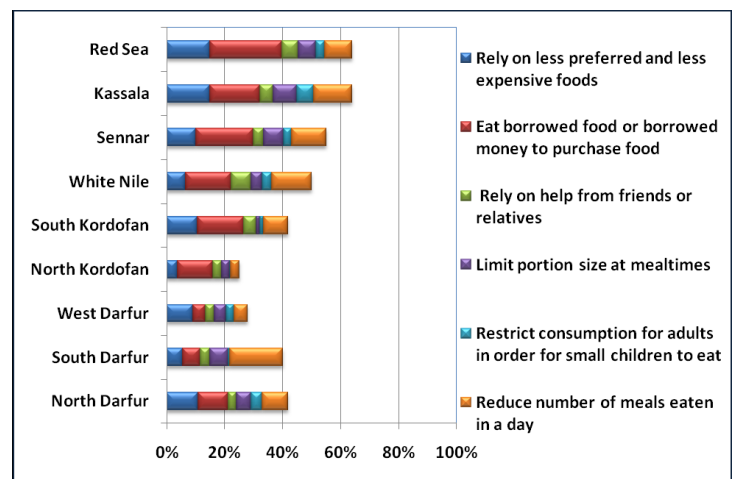

Figure 4: Food security coping strategies [10].

\section{Data and Methodology}

\section{Study area}

Geographical background of Al-Qadarif state: Al-Qadarif State is in the eastern part of Sudan and extends over an area of about 72,000 $\mathrm{km} 2$ (Figure 4). The state is bordered to the east by Ethiopia and Eritrea. The four Sudanese states surrounding Al-Qadarif State are Khartoum, Kassala, Gezira and Sinnar. The mean temperature in the $\mathrm{Al}$-Qadarif town is $29^{\circ} \mathrm{C}$, the mean maximum is $37^{\circ} \mathrm{C}$ and the mean minimum is $21^{\circ} \mathrm{C}$. May is the hottest month of the year. The area is characterized by a unimodal rainfall season most of which primarily occurs from June to September and controlled by the nature of the Inter Tropical Convergence Zone. The annual rainfall in the area ranges between less than $300 \mathrm{~mm}$ in the North to more than $800 \mathrm{~mm}$ in the South [24].

Analysis of climatic records from Al-Qadarif meteorological station by Sulieman and Elagib [25] showed that there is significant warming of the climate, increasing rainfall variability and seasonality and intensifying aridity conditions during the start and end of the wet season. Also, there is an increase in rainfall concentration.

The dominant soil in the study area is dark, heavy, deep clay belonging to the vertisol group, which cracks widely during the dry season and expands during the wet season due to the high content of clay. This type of soil becomes very sticky in wet seasons. Clay soil in the area has a potential problem, as infiltration capacity and permeability when moist would be too low when it is dried. The management of vertisols is very difficult because of constraints caused by chemical and physical characteristics. The distribution of natural vegetation in the region depends largely on two factors: rainfall and soil. The amount of annual rainfall and the length of the rainy season, which vary along the climatic gradient from north to south, have significant impact on seasonal vegetation dynamics [24].

Classified the vegetation cover of the study area into three major vegetation zones [26]: semi desert vegetation cover in the north followed by low woodland savannah in the central part of the state and high woodland savannah in the far south. However, the study area affected by changing in the climate factors such as temperature and rainfall, this climate changes affect the agriculture production particularly sorghum production [3] found that there is a positive relationship between sorghum and rainfall, this means an increase in rainfall enhances sorghum production; while its decrease results in poor sorghum yield. On the other hand, both maximum and minimum temperature showed a negative relationship. This implies that an increase in temperature beyond the optimum level (elevated temperature of about $26^{\circ} \mathrm{C}$ to $30^{\circ} \mathrm{C}$ and low temperature of about $10^{\circ} \mathrm{C}$ to $15^{\circ} \mathrm{C}$ ) results in a decline in sorghum production and vice versa.

Population and land use: According to the 2008 census, the total population of Al-Qadarif State is 1,336,662 persons with an annual population growth rate of $4.7 \%$, which is higher than the national growth rate [4].

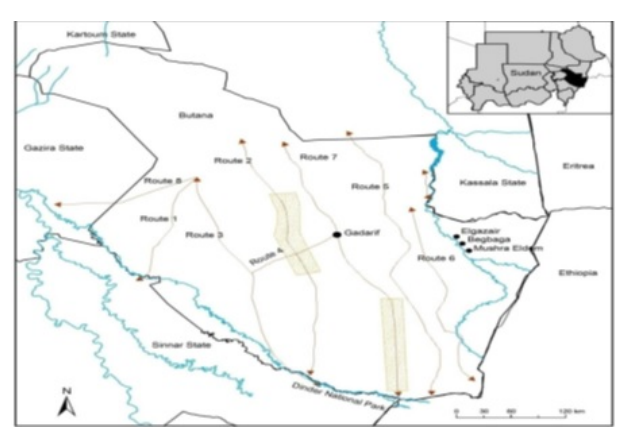

Figure 5: Map of Al-Qadarif state [24].

Followed agriculture, livestock rearing is the second economic activity in different forms, namely traditional seasonal transhumant, village livestock raising and, as a recent element, livestock raising by large scale mechanized merchant-farmers investing surplus wealth in sheep and cattle (Figure 5). 
Collecting and trading forest products and charcoal burning are other traditional forms of economic activity. Thus, the people derive their livelihood income from a mixture of combinations of the three main forms of land use: Agriculture, grazing and forest utilization. Livestock production in the state is dominated by pastoral and agropastoral traditional systems.

\section{Research Methodology}

\section{Questionnaire development}

To determine the state of the food security within the state the USA household food security survey module: Six-item short has been adopted. The six-item short form of the survey module and the associated six-item food security scale were developed by researchers at the National Center for Health Statistics in collaboration with Abbott Laboratories (Abt) Associates Inc.

If respondent burden permits, use of the 18-item USA household food security survey module or the 10-item USA adult food security survey module is recommended. However, in surveys that cannot implement one of those measures, the six-item module may provide an acceptable substitute. It has been shown to identify food-insecure households and households with very low food security with reasonably high specificity and sensitivity and minimal bias compared with the 18-item measure. It does not, however, directly ask about children's food security, and does not measure the most severe range of adult food insecurity, in which children's food intake is likely to be reduced.

The food security questions in the 6-item module are essentially unchanged from those in the original module first implemented in 1995, but some adjustments have been done such as:

- In September 2012: A coding specification for "How many days" for 30-day version of AD1a has been added.

- In July 2008: Wording of resource constraint in AD2 was corrected to, "...because there wasn't enough money for food" to be consistent with the intention of the September 2006 revision.

- In January 2008: User notes for coding AD1a have been corrected.

- September 2006:

Minor changes were introduced to standardize wording of the resource constraint in most questions to read, "...because there wasn't enough money for food."

Question numbers were changed to be consistent with those in the revised household food security survey module.

User notes following the questionnaire were revised to be consistent with current practice and with new labels for ranges of food security and food insecurity introduced by USDA in 2006.

The six questions in the module are concerning the accessibility to the food, sustainability of food accessing to all people and the utilization and of the food e.g. Question HH3 is about sufficiency of food and HH4 is related to ability to buy or you can say to access balanced food and so on. AD1 measures accessibility throughout the year.

Coding responses and assessing households' food security status: Responses of "often" or "sometimes" on questions HH3 and HH4, and "yes" on $\mathrm{AD} 1, \mathrm{AD} 2$, and $\mathrm{AD} 3$ are coded as affirmative (yes). Responses of "almost every month" and "some months but not every month" on
ADla are coded as affirmative (yes). The sum of affirmative responses to the six questions in the module is the household's raw score on the scale.

\section{Assigning the status food security}

\section{Food security status is assigned as follows:}

- Raw score 0-1- High or marginal food security (raw score 1 may be considered marginal food security, but a substantial proportion of households that would be measured as having marginal food security using the household or adult scale will have raw score zero on the six-item scale).

- Raw score 2-4- Low food security.

- Raw score 5-6 Very low food security.

\section{Sampling}

For the household questionnaire sample size has been determined by using the Kerjcie and Morgan table [27], Which came out from this equation:

$$
\mathrm{S}=\mathrm{X} 2 \mathrm{NP}(1-\mathrm{P}) \div \mathrm{d} 2(\mathrm{~N}-1)+\mathrm{X} 2 \mathrm{P}(1-\mathrm{P})
$$

$\mathrm{S}=$ required sample size.

$\mathrm{X} 2=$ the table value of chi-square for 1 degree of freedom at the desired confidence level (3.841).

$\mathrm{N}=$ the population size, $\mathrm{P}=$ the population proportion (assumed to be 0.50 since this would provide the maximum sample size).

\begin{tabular}{|l|l|l|l|l|}
\hline No. & Localities & $\mathbf{( 2 0 1 5 )}$ Population & $\%$ & Sample size \\
\hline 1 & Al-Fashaga & 172613 & 9 & 35 \\
\hline 2 & Al-Fau & 249329 & 13 & 50 \\
\hline 3 & Western El-Galabat & 134254 & 7 & 27 \\
\hline 4 & El-Guraisha & 115075 & 6 & 23 \\
\hline 5 & Eastern El-Galabat & 153434 & 8 & 31 \\
\hline 6 & Bassonda & 76717 & 4 & 15 \\
\hline 7 & El-Mafaza & 95896 & 5 & 19 \\
\hline 8 & El-Rahad & 191792 & 10 & 38 \\
\hline 9 & El-Buttana & 95896 & 5 & 19 \\
\hline 10 & Qualia-Nemaha & 95896 & 5 & 19 \\
\hline 11 & El-Al-Qadarif & 383584 & 20 & 77 \\
\hline 12 & Rural El-Qadarif & 153434 & 8 & 31 \\
\hline & Total & $2 E+06$ & 384 \\
\hline
\end{tabular}

Table 1: Distribution for the household questionnaire the desired sample size [7].

$\mathrm{D}=$ the degree of accuracy expressed as a proportion (0.05). The total sample size was 384 , it would be distributed between the localities using stratified technique, according to their population, and the sample size is in the following (Table 1). 


\section{Data analysis}

The SPSS software used to analyse primary data collected by means of questionnaire (questionnaires). Descriptive statistics using percentages and frequencies employed to give some insights about FSN situation in the State, and challenges that faces the implementation. Descriptive statistics employed to analyse food security situation based on responses of households. Chi square used to test the association between policy makers opinion at the state and locality level for Availability of FSN policy in the state.

The model used to determine the variables that affecting food security status in the state and the relation between food security status in the state and some social characteristic:

$\mathrm{Y}=\mathrm{a}+\mathrm{bXi}$

Where:

Y=Food security status, (Secured or marginal/ low food security/ very low food security).

a or Alpha=A constant; equals the value of $\mathrm{Y}$ when the value of $\mathrm{X}=0$

$\mathrm{b}$ or Beta=The coefficient of $\mathrm{X}$; the slope of the regression line; how much $\mathrm{Y}$ changes for each one-unit change in $\mathrm{X}$. $\mathrm{X} 1=\mathrm{Gender}$; $2=$ Age; $\mathrm{X} 3=$ Number of Children; X4= Education Level; and X5=Job.

\section{Results and Discussion}

The Status of the Households Food Security in the State:

Stated that the main constraints that prevent regular and reliable reporting on trends in food insecurity and hunger in South Africa, have been identified as:

- The lack of recent national data.

- The use of different methodologies and criteria for selecting respondents and

- The relatively extended period between nutritional surveys.

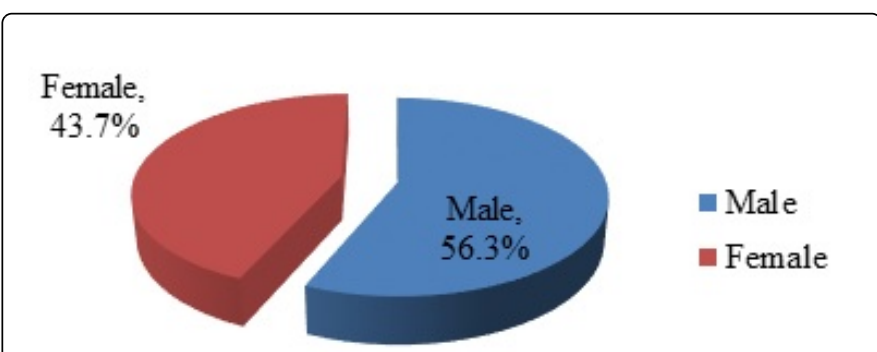

Figure 6: Distribution of the respondents of the household according to their gender [28].

So, in this study to determine the household's food security among the state the "USA Household Food Security Survey Module: Six-Item Short Form" has been adopted, as one of the simplest method to find out the status of the household in the State.

This Figure 6 shows that the female represents $43.7 \%$ of the respondents, and this is a good sign, and reflects the women role in their society.

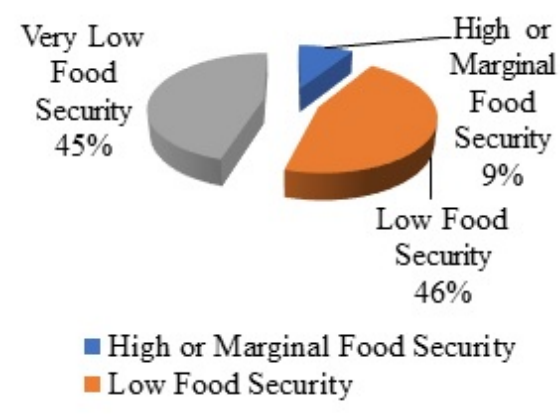

Figure 7: Household food security status for the whole state.

The result in Figure 7 achieved by using the USA household food security survey module: six-item short form economic research service, USDA [29].

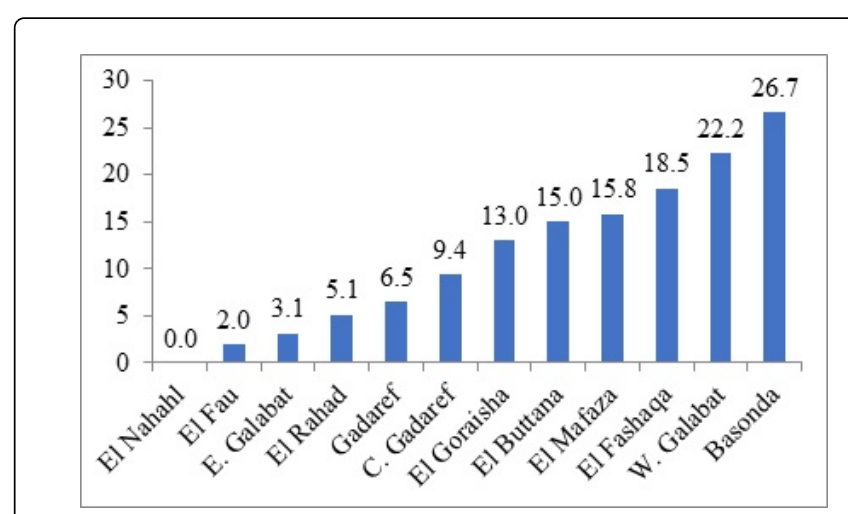

Figure 8: Distribution of the secured households (high/marginal food security status), by the localities.

This figure shows that only $9 \%$ of the respondents at household scored 0-1 raw score according to the coding responses in the six-item module, so they are in high or marginal food security status, $46 \%$ of them scored 2-4 and 45\% of scored 5-6 in the coding responses which means that more than $91 \%$ of the household are suffering from food insecurity in the two various levels. This result is apposite to the household food security status in the State that mentioned in Hassan [30] report which was almost $89 \%$ of the household are food secured. This is because the report is about the supply side for food security.

This Figure 8 shows the distributions of the secured households, which was only $9 \%$ of the respondents in the state. For each locality, Bassonda locality has the highest percentage of the secured households, $26.7 \%$ of the respondents, and E-lNahal locality in the bottom of the list, with $0 \%$ of the respondents.

\section{The Relationship between food security status and some social characteristic}

There are some factors may affect the household food security status in the state such as: age, gender, education, job and number of children, we use the regression and correlation analysis, to test this relation. 
Page 9 of 12

\begin{tabular}{|l|l|l|l|}
\hline Dependent variable & $\begin{array}{l}\text { Independent } \\
\text { variables }\end{array}$ & $\mathbf{R}$ & $\begin{array}{l}\text { Sig (p- } \\
\text { value) }\end{array}$ \\
\hline $\begin{array}{l}\text { Food security status of the households: } \\
\text { (High/marginal food security, low food } \\
\text { security and very low food security). }\end{array}$ & Gender & $\begin{array}{l}0.01 \\
6\end{array}$ & 0.756 \\
\cline { 2 - 4 } & Age & $\begin{array}{l}0.13 \\
7\end{array}$ & 0.006 \\
\cline { 2 - 4 } & No of children & $\begin{array}{l}0.00 \\
0\end{array}$ & 0.989 \\
\cline { 2 - 4 } & Education level & $\begin{array}{l}0.10 \\
4\end{array}$ & 0.039 \\
\cline { 2 - 4 } & Job & $\begin{array}{l}0.09 \\
8\end{array}$ & 0.052 \\
\hline
\end{tabular}

Table 2: Correlation analysis to determine the relation between food security and some of the social characteristic.

Table 2 shows that there was some relation between dependent variable, food security of the households, and some independent variables which are gender, age, number of the children, educational level and the household jobs, however, there was a significant relationship between food security status as dependent variable and age and education level as independent variables, with a significant $\mathrm{P}$ value of 0.006 and 0.039 respectively.

\begin{tabular}{|l|l|l|l|}
\hline Dependent variable & $\begin{array}{l}\text { Independent } \\
\text { variables }\end{array}$ & Beta & $\begin{array}{l}\text { Sig (p- } \\
\text { value) }\end{array}$ \\
\hline $\begin{array}{l}\text { Food Security Status of the households: } \\
\text { (High/Marginal Food Security, Low Food } \\
\text { Security and Very Low Food Security). }\end{array}$ & Gender & $\begin{array}{l}0.03 \\
4\end{array}$ & 0.550 \\
\cline { 2 - 4 } & Age & $\begin{array}{l}0.18 \\
0\end{array}$ & 0.002 \\
\cline { 2 - 4 } & No of Children & $\begin{array}{l}0.07 \\
3\end{array}$ & 0.208 \\
\cline { 2 - 4 } & Education level & $\begin{array}{l}0.09 \\
0\end{array}$ & 0.091 \\
\cline { 2 - 4 } & Job & $\begin{array}{l}0.14 \\
1\end{array}$ & 0.013 \\
\cline { 2 - 4 } & & &
\end{tabular}

Table 3: Regression analysis to determine the variables that affecting the food security and some social characteristic.

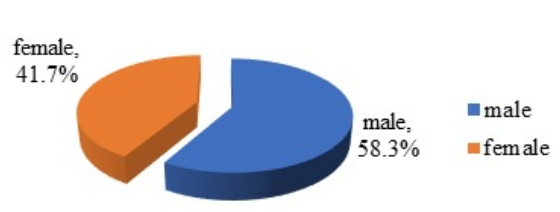

Figure 9: Distribution of the secured household sample according to their gender.

Table 3 shows that the main factors that affecting the household food security status are age and job with significant $\mathrm{P}$ value 0.002 , 0.013 and 0.091 respectively.

\section{Gender}

Figure 9 shows that male is more likely to be food secured with a percentage of $58.3 \%$ of the secured sample and only $41.7 \%$ for the female.

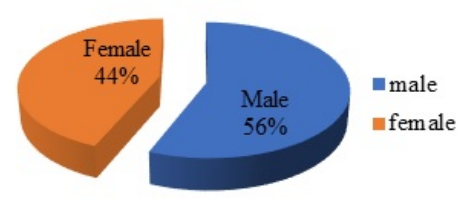

Figure 10: Distribution of the in-secured household sample according to their gender.

This Figure 10 shows that male is more likely to be food in-secured with a percentage of $56.1 \%$ of the in-secured sample and only $43.9 \%$ for the female.

The above results in Figure 9 and Figure 10 may come from the nature of the total sample distribution; about $56.3 \%$ of the total respondents were male and the rest $43.7 \%$ were for female.

\section{Age}

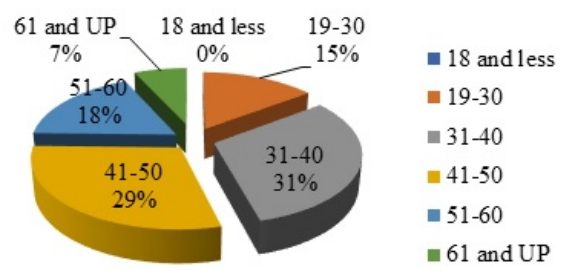

Figure 11: Distribution of the total household sample according to their age.

This Figure 11 shows the distribution of the total sample of the household in the State, the age distribution is ranged between $19-85$ years with $31.2 \%$ of the household in the age ranged between $31-40$ and $6.9 \%$ of the household in the age group of 61-85 years.

Age has an important effect in productivity and output of the individual as it affects the mental and the manual abilities. Many writers reported that, age has a positive effect on productivity until a certain level beyond which it would have a negative effect [31] Figure 11 shows the age distribution in the secured household of the sample. As we see in the figure the age is ranged between 20-70 years with $33.3 \%$ of the food secured respondents their age distributed in the age range of 31-40 year and the lowest percentages are for the youngest and the elders age groups with $00.0 \%$ for the age group less than 18 years and $5.6 \%$ for those above 60 years of the secured household sample (Figure 12). 


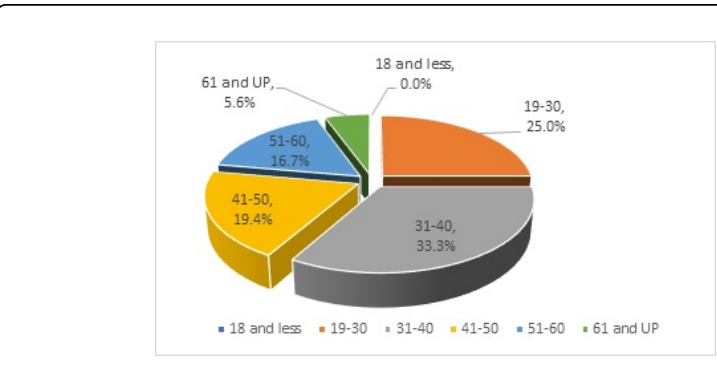

Figure 12: Distribution of the secured household sample according to their age.

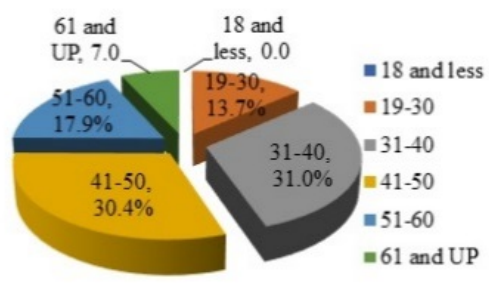

Figure 13: Distribution of the In-secured household sample according to their age.

In the Figure 13 the age is ranged between $20-70$ years with $31.0 \%$ of the food in-secured respondents, their age distributed in the age range of 31-40 year and the lowest percentages are for the youngest and the elders age groups with $00.0 \%$ for the age group less than 18 years and $7.0 \%$ for those above 60 years of the in-secured household sample.

\section{Children}

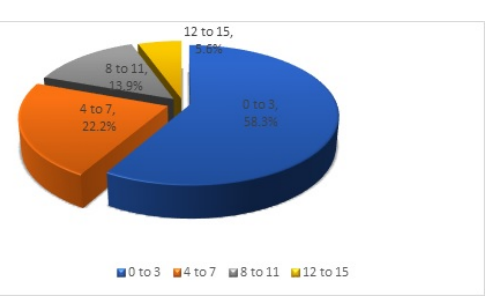

Figure 14: Distribution of the secured household sample according to the number of their children.

Figure 14 shows the number of the children range between 0 to 15 children, about $58.3 \%$ of food secured household of the sample have three children or less and only $5.6 \%$ of them have 12 children or more.

Figure 15 shows about $41.9 \%$ of food in-secured household of the sample have four to seven children and only $2.8 \%$ of them have 12 children or more and this may be because of the percentage of the household with 12 or more children is only $3.04 \%$ of the total sample.

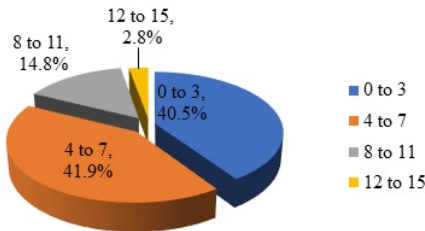

Figure 15: Distribution of the in-secured household sample according to the number of their children.

\section{Education}

In developing countries, where technological change is radically altering life style, education is necessary for survival, it helps people to understand and benefit from change and obtain their economic rights [32].

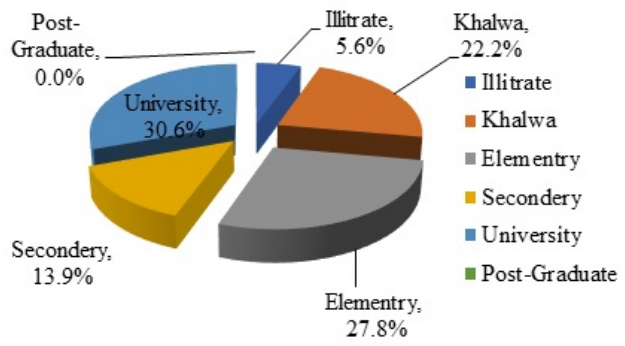

Figure 16: Distribution of the secured household sample according to their education level.

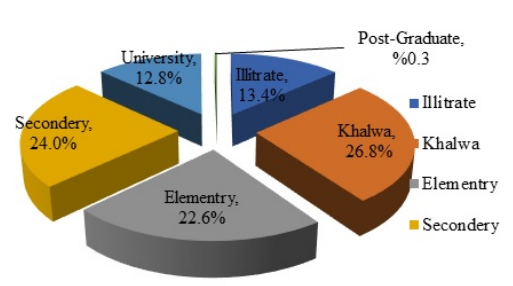

Figure 17: Distribution of the in-secured household sample according to their education level.

Figure 16 shows that about $30.6 \%$ of the food secured household had a university degree and, $5.6 \%$ of them were illiterate and none of them had a post-graduate degree.

Figure 17 shows that only $13.1 \%$ of the food in-secured household graduate and post-graduate and about $40.2 \%$ of them had not any formal education either they are illiterate or went to Khalwa. The above Figures 16 and 17 shows that education plays a key role in helping household to satisfy their food needs, Figure 16 shows only $5.6 \%$ of the food secured households were illiterate and Figure 17 shows only $12.8 \%$ of the food in-secured household have a university degree. 
Page 11 of 12

\section{Job}

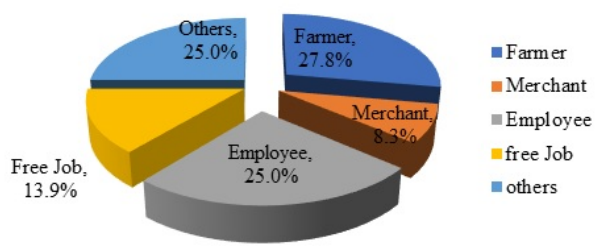

Figure 18: Distribution of the secured household sample according to their job.

Figure 18 shows about $27.8 \%$ of the food secured house hold sample were farmers and only $8.3 \%$ of them were merchants and that might be due to their weight in the total sample the merchants only represent $3.6 \%$.

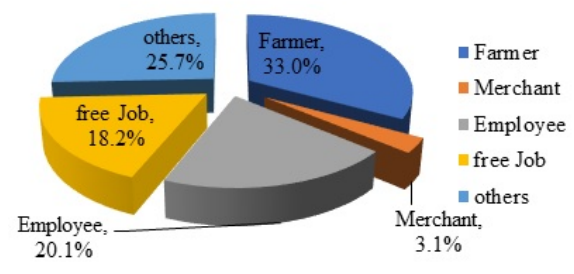

Figure 19: Distribution of the in-secured household sample according to their job.

Figure 19 shows about $33.0 \%$ of the food in-secured house hold sample were farmers and only $3.1 \%$ of them were merchants.

\section{Coping Strategies of the Household}

In this section, here are some coping strategies adopted by household in Al-Qadarif state when faced food insecurity.

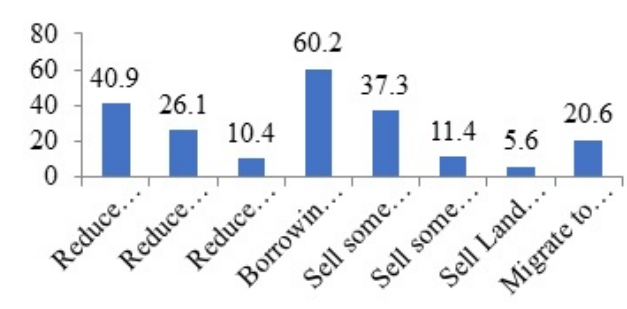

Figure 20: Some coping strategies of the household.

Households in Northern Sudan apply a variety of coping strategies, the most common being to rely on less preferred or less expensive food or eat borrowed food or borrow money to buy food, and more severely to reduce the number of meals eaten in one day [30]. So, the households of Al-Qadarif State were not apart from those strategies, Figure 20 shows most of the household in the State, (60.2\%), borrowed to meet their food needs as one of their coping strategy and only $5.6 \%$ sell their fixed assets.

\section{Conclusion}

From all the previous information the following have been concluded:

- About $46 \%$ of the population in a very low food security condition.

- There is a significant relationship between food security status as dependent variable and age and education level as independent variables and the main factors that affecting the household food security status are age and job with significant $P$ value of 0.002 and 0.013 respectively.

\section{Recommendation}

Some interventions in all FSN dimensions may be recommended as following:

\section{Availability side}

- Use the modern technologies to increase the productivity of the crops, such as: using improved seeds, fertilizers, new techniques, and fallow etc.

- Use the modern technologies to increase the productivity of the animal productions.

- Increase the storing capacity.

- Insert some of the transformation industries.

- Improve quantity of the drinking water.

\section{Accessibility side}

- Connect the rural areas to the electricity network.

- Connect production areas with good roads net.

- Ease the collateral conditions to get microfinance, and follow the implementation.

- Expand the direct and indirect aids from MoSA.

\section{Utilization side}

- Improve the public health situation.

- Improve quantity of the drinking water.

- Improve quality of the drinking water.

\section{Sustainability side}

- Build FSN policy/strategy to put the natural resources conservation in consideration (here an administrative secretary is recommended to follow the execution of the regulations issued by the State Legislative Council.

- Give the SFSTS a power to conduct their recommendation and follow the implementation (for this an independent full time General Director is highly recommended to lead FSN.

\section{References}

1. WSFS (2009) Declaration of the World Summit on Food Security Rome, Italy.

2. McGuire S (2015) The state of food insecurity in the world: Meeting the 2015 International hunger targets: taking stock of uneven progress. Rome: FAO, Advances in Nutrition: An International Review Journal 6: 623-624.

3. Berry L, Area Hand Book: Sudan (A Country Study).

4. CBS (2012) Fifth population and housing census government of Sudan, Sudan. 
5. FAO/EWSFA (1997) Crop and Food Supply Situation in Sudan

6. http://www.ruralpovertyportal.org/web/rural-poverty-portal/country/ home/tags/sudan

7. CBS (2012) Fifth Population and Housing Census, Sudan.

8. IPC (2015) Integrated Food Security Phase Classification, Sudan.

9. Gross R., Schoeneberger H, Pfeifer H, Preuss HJA (2000) The four dimensions of food and nutrition security: Definitions and concepts. SCN News. 20: 20-25.

10. FAO, IFAD, IMF, OECD, UNCTAD, et al. (2011) price volatility in food and agricultural markets: Policy responses.

11. Bickel G, Nord M, Price C, Hamilton W, Cook J (2000) Guide to measuring household food security. United States Department of Agriculture.

12. FAO (2003) Measurement and assessment of food deprivation and undernutrition. Food and Agriculture Organization of The United Nations.

13. Naiken L (2003) FAO methodology for estimating the prevalence of undernourishment.

14. Jensen HH (2001) Qualitative measures of food insecurity and hunger: Discussion. Measurement and Assessment of Food Deprivation and Under-Nutrition. Iowa State University, USA.

15. Dercon S (2001) Assessing vulnerability. Publication of the Jesus College and CSAE, Department of Economics, Oxford University, UK.

16. Kennedy E (2003) Qualitative measures of food insecurity and hunger. FAO.

17. Nord M, Satpathy AK, Raj N, Houser R (2002) Comparing household survey-based measures of food insecurity across countries: Case studies in India, Uganda, and Bangladesh. Working Papers in Food Policy and Nutrition.

18. Coates J, Webb P, Houser R (2003) Measuring food insecurity: Going beyond indicators of income and anthropometry. Food and Nutrition Technical Assistance Project, Academy for Educational Development.

19. Bickel G (2000) Guide to measuring household food security. US Department of Agriculture, Food and Nutrition Service, Office of Analysis, Nutrition, and Evaluation.
20. Blumberg SJ, Bialostosky K, Hamilton WL, Briefel RR (1999) The effectiveness of a short form of the Household Food Security Scale. Am J Publ Health 89: 1231-1234.

21. Maxwell D, Caldwell R (2008) The coping strategies index: Field methods manual. Atlanta, Georgia: CARE.

22. CFSAM (2015) Crop and Food Security Assessment Mission to the 15 Northern States of Sudan, Sudan.

23. Novella NS, Thiaw WM (2013) African rainfall climatology version 2 for famine early warning systems. J Appl Meteorol Climatol 52: 588-606.

24. Sulieman HM (2013) Land grabbing along livestock migration routes in Gadarif State, Sudan. LDPI Working Paper 19. The Land Deal Politics Initiative, The Hague.

25. Sulieman H, Elagib N (2012) Implications of climate, land-use and landcover changes for pastoralism in eastern Sudan. J Arid Environ 85: 132-141.

26. Harrison M, Jackson JK (1958) Ecological classification of the vegetation of the Sudan.

27. Krejcie RV, Morgan DW (1970) Determining sample size for research activities. Educ Psychol Meas 30: 607-610.

28. Koch J (2011) The food security policy context in South Africa. Country Study, International Policy Centre for Inclusive Growth.

29. Cook JT, Black M, Chilton M, Cutts D, Ettinger De Cuba S, et al. (2013) Are food insecurity's health impacts underestimated in the US population? Marginal food security also predicts adverse health outcomes in young US children and mothers. Adv Nutr 4: 51-61.

30. CFSAM (2011) Government of Sudan and FAO/WFP Crop and Food Security Assessment Mission to the 15 Northern States of Sudan.

31. Hassan HHI (2015) Technical efficiency of wheat production in Rahad Scheme, Sudan.

32. Elnour SA (1996) Economic evaluation of crop combination in Rahad Scheme. 